\title{
Aesthetic Cognitivism: Towards a Concise Case for Doctoral Research through Practices in the Visual Arts
}

\author{
Howard Riley PhD MA(RCA) CertDes FRSA FHEA \\ Professor Emeritus, Swansea College of Art \\ University of Wales Trinity Saint David \\ Wales, UK \\ howard.riley@btinternet.com \\ ORCiD iD: orcid.org/0000-0002-8682-2587
}

\begin{abstract}
This article addresses a question still frequently posed in the context of UK universities which offer courses in the visual arts: Does the PhD research model of contributing new knowledge fit art, where there are no definitive answers and the main strength of the research is its ability to question?, answering in the positive by distinguishing between propositional knowledge, and understanding. It acknowledges the range of work already published on this topic, and distils an aesthetic cognitivist position from which the visual arts are construed as powerful means of deepening our understanding, a source of nonpropositional knowledge on a par with, although qualitatively different from, the way that the sciences are construed as the means to propositional knowledge.

The distinguishing feature of the article is its attempt to provide a relatively concise overview of the background and structure of the case for the inclusivity of research through visual arts practices at doctoral level in the universities, based upon an aesthetic cognitivist position which I hope will support research supervisors and others charged with advocating the viability of practice-based or practice-led doctoral proposals ${ }^{1}$ in university crossdisciplinary research degrees’ committees.
\end{abstract}

\section{Keywords}

Types of knowledge; Aesthetic cognitivism; Visual arts research; Inclusivity

\section{Preface}

The practice and experience of art is as important to man (sic) as the use and knowledge of science. These two great manners of apprehending and enjoying existence are complementary, not hostile. The specific value of art for man is that it is closer to reality than science; that it is not dominated, as science must be, by logic and reason; that it is therefore essentially a liberating activity, while science for excellent and necessary causes - is a constricting one. Finally and most importantly it is the best, because richest, most complex and most easily comprehensible, medium of communication between human beings.

(Fowles 1980:174)

The key word is complementary. John Fowles sustains my effort to contribute at least a degree of perspicacity into the argument that the visual arts are as potent a means towards knowledge, understanding, and the illumination of human experience as the sciences. It has been found problematical to evaluate research outcomes in the visual arts concerned with 
qualitative issues such as insights to the understanding of human perception and cultural communication, from within the dominant university research culture more used to dealing with outcomes measureable in terms of scientific application and economic impact. However, I hope to demonstrate later in this article that through different ways of looking, we are able to think differently; and through different ways of making visible those perceptions (via drawing and other visual codes) we are able to share those different ways of thinking.

\section{The Problem}

Before specifying the problem in its contemporary guise, it is useful to take a historical view:

The separation of science and technology from art was the mind-set driving the network of the UK Government Schools of Design set up in 1842 to produce designers who, it was envisioned, would add visual appeal to the mass-produced output of the manufacturing industries which were proliferating at that time, thus stimulating the 'desire to acquire' so essential in a mass-production/mass-consumption capitalist economy. However, by 1849 it was apparent that the Schools of Design were not fulfilling their intended purpose, but were attracting instead students desiring to maintain a cohesion between design and technological skills and the fine arts, and so, following a Parliamentary Select Committee, Henry Cole was appointed director of the reconstituted schools which became known as Schools of Art, with an added remit as “...centres of instruction for public education in drawing.” (Macdonald 1973: 91). Prior to 1961, when the Diploma in Art \& Design (DipAD) was introduced to replace the National Diploma in Design (NDD) which had been in operation since 1946, provincial art schools were, in the main, preparing students for professional practices. 'Research' was not on the agenda, 'outputs' were generally artefacts made for exhibition, or the results of craft and design activities related to local traditions and requirements. The shift towards Polytechnic structures in the late 1960s (typically, amalgamations of regional technical colleges, teacher-training colleges and art colleges) and the re-classifying of the DipAD as the Bachelor of Arts (BA) degree in1974, meant that those art schools who desired national recognition (the alternative was parochial oblivion!) found themselves on an academic par with the other disciplines. Since 1992, when Further and Higher Education Acts re-branded the Polytechnics as new universities, this parity has been brought under closer scrutiny. The staff of the previously 'non-academic' training programmes - Sally Findlow (2012: 118) lists nursing, physiotherapy, social work, teaching and business studies, I would add art and design now find themselves in an uncomfortable position: as Findlow observes, “... in addition to 'non-traditional' students, higher education institutions... are now staffed by large numbers 
of 'non-traditional' lecturers for whom assuming an academic identity...” (with its concomitant responsibilities for articulating, demonstrating and developing the theoretical bases of their pedagogies, as well as engaging in research activities distinct from normal professional practice) “...can be problematic.”

That's not the full extent of their problems - see Ben Martin's (2016) article for a comprehensive review - today, those staff are also charged with a range of administrative imperatives imposed by their institutions' managers competing alongside the older established universities in a commercial environment, including responsibilities for the recruitment and retention of students, the monitoring of student attendance, even of the activities and movements of their overseas students on behalf of the visa authorities, all in the context of...

...multi-dimensional markets (national and international students, research, enterprise), they (staff) are required to maintain solvency and comply with national benchmarks and legal frameworks, to produce high quality research work, keep student consumers happy, produce good graduates - the list of imperatives grows. (Findlow 2012:118)

Such changes in the structuring of UK higher education affecting the art schools, culminating in their being incorporated within the university sector by 1992, and thereafter eligible for inclusion in the national research assessment exercises, RAE 1996, 2001, 2008, and the research excellence framework, REF 2014, 2021, have revealed the historical confusion over the status of research in the visual arts as a means of contributing to knowledge and understanding.

This confusion has been exacerbated because university research regulations remain vague about what knowledge and understanding mean in the context of the visual arts, whilst prioritising propositional knowledge, generally assumed to involve “...justified true belief...” (Gettier 1963), over other types of knowledge. Kristina Niedderer (2007: 5-6) has shown (in Niedderer 2007a) that this understanding of propositional knowledge is...

...implicit in the definition of research because of additional requirements such as the textual/written presentation of an intellectual position (proposition, thesis 'true belief'), because of the logic of verification and defence of this intellectual position through argument and evidence (justification), and the requirement for generalisability/transferability and explicit and unambiguous communication.

Whilst virtually all theorists agree that true belief is a necessary condition for knowledge, there is a longstanding refutation of the condition of justification, as demonstrated by Edmund Gettier (1963), famous in Anglo-American epistemology for his paper - all of three pages! - attacking the tripartite definition of knowledge. This defines ' $S$ knows that $p$ ' as: 


\author{
$S$ believes that $p$ \\ $S$ 's belief that $p$ is justified
}

Gettier showed that this definition is insufficient, he argued that one's true belief might be justified in a way that depends upon chance: for example, consider an analogue clock which is normally accurate but happens to have stopped, and an observer who reads it at one of the two precise moments in 24 hours when it shows the correct time. In such a case, the reader has true belief which is justified, but is not knowledge.

So it would be safer to regard the theoretical basis of propositional knowledge as a means towards generalised abstractions - rich though they may be - rather than as the exclusive means to a deeper understanding of the world and our relationships within it. The historical prioritisation of propositional knowledge has excluded the kinds of knowledge associated with visual art practices, which have variously been called 'practical', 'personal', 'procedural' or 'tacit' knowledge, and 'experiential' knowledge, all of which I shall include under the collective term non-propositional.

\title{
Towards an Aesthetic Cognitivist Position
}

Could an elaboration of the terms 'knowledge' and 'understanding' resolve the misunderstandings that occur between academic research disciplines in their common quest for...knowledge and understanding?

The genesis of the debate about the status of visual arts practice as research within a UK higher education context can be traced back to 1997, when a Working Group under the auspices of the UK Council of Graduate Education and convened by Professor Christopher Frayling, then Rector of the Royal College of Art, was articulating the position of doctoral research within the art schools:

...the practice-based doctorate advances knowledge partly by means of practice. An original piece of work is included in the submission for examination. It is distinct in that significant aspects of the claim for doctoral characteristics of originality, mastery and contribution to the field are held to be demonstrated through the original creative work.

Practice-based doctoral submissions must include a substantial contextualisation of the creative work. This critical appraisal or analysis not only clarifies the basis of the claim for the originality and location of the original work, it also provides the basis of a judgement as to whether general scholarly requirements are met. This could be defined as judgement of the submission as a contribution to knowledge in the field, showing doctoral level powers of analysis and mastery of existing contextual knowledge, in a form which is accessible to and auditable by knowledgeable peers. (Frayling 1997:14) 
It is clear that the Group was defining a cautious, "situated” position, in Michael Biggs' and Daniela Buchler's (2008: 5) description of practice-based arts research as integrated within the general academic research community, but one which still required specific guidance for doctoral candidates with an art school background.

Such guidance should emphasise Frayling's general scholarly requirements, particularly the inclusion of a review of the recognised paradigms of research, the criteria of assessment applicable to each paradigm, (Denzin and Lincoln 2005), together with a reasoned argument for the adoption of the chosen paradigm (or mix of paradigms, or for a new one) and the criteria by which the chosen one is justified. After all, the doctorate is a licence to research, and to supervise the research of others; it is confirmation of an understanding of the whole research process, not simply a demonstration of professional practice.

The Group’s contribution built upon a crucial insight of Nelson Goodman (1978: 21-2):

...knowing cannot be exclusively or even primarily a matter of determining what is true...Much of knowing aims at something other than true, or any, belief. An increase in acuity of insight or in a range of comprehension, rather than a change in belief, occurs when....we see...features and structures we could not discern before. Such growth in knowledge is not by formation or fixation of belief but by the advancement of understanding.

(My italics)

The differentiation between knowledge and understanding identified by Goodman and elaborated by his erstwhile colleague Catherine Z. Elgin (2002, 2006), serves to support my position: that the aim of our cognitive activities related to visual arts practices is to increase our understanding, rather than to generate true beliefs, justified or not. I intend to introduce the case for an aesthetic cognitivist position, how research through such practices can enhance our understanding of the world, advocating a sociological approach which explores the concept of visual art in terms of its value within social contexts, as opposed to the alternative main approach to the general study of Western art, that of analytical philosophy which instead seeks to define what art is.

Within the sociological tradition, theories aiming to explain value are classed as normative since they attempt to establish a standard, a norm. Gordon Graham (1997: 46) reviews three such normative positions: firstly, the idea that the value of art lies in its capacity to give pleasure, aestheticism; secondly, that art's value lies in its abilities to facilitate the expression of emotion, expressivism; and thirdly, that art is valuable as a source of understanding, cognitivism. This article takes the view that the most socially-useful value of visual arts research lies in its scope for contributing to our understanding of our 
experiences of the world, without denying the social functions of art practices as a source of pleasure or a means of self-expression.

Cognitive value refers to the potential of an artwork to facilitate learning, to intrigue the brain through the engagement of imagination; Michael Craig-Martin’s 1973 An Oak Tree, provoking insights into the nature of representation, and Robert Rauschenberg's 1953 Erased de Kooning Drawing inviting alternative perspectives on concepts of ownership, authorship, are good examples of such potential. Aesthetic value refers to the potential of an artwork to intrigue the eye; the works of Bridget Riley, and Patrick Hughes' series of Reverspectives (www.patrickhughes.co.uk) foreground this value. Note that none of these works exhibits a high degree of balance between conceptual intrigue and perceptual intrigue. Could such a criterion - the degree of balance - be relevant in the evaluation of research in the visual arts? 'Conceptual intrigue' refers to how a work can afford viewers fresh insights which stimulate new understandings of the theme or concept to which it alludes, and 'perceptual intrigue' refers to how the artist's manipulation of the material qualities of the work might stimulate perceptual experiences which cause the viewer's gaze to linger, and perceptual complacencies to be challenged.

(Later in this article I offer the practice-based research of Robert A. Newell as an example of a high degree of balance between the two.)

Thus, we consolidate the aesthetic cognitivist position articulated by Goodman (1978: 102):

...the arts must be taken no less seriously than the sciences as modes of discovery, creation, and enlargement of knowledge in the broad sense of advancement of the understanding, and thus that the philosophy of art should be conceived as an integral part of metaphysics and epistemology.

However, the sense of imbalance between the perceived value of the sciences and the arts as sources of knowledge and the advancement of understanding evident in Goodman's wording of nearly forty years ago still retains some resonance today in university crossdisciplinary research committees, despite the robust efforts of members of the academic artworld to transform government understanding of the role of creative practices, to the extent that practice-based research in the visual arts has become eligible for funding, and is recognised by the research assessment exercises. Such robust articulation has relied upon understanding which knowledge set, or knowing what kind of understanding, the art schools are best placed to articulate. 


\section{Knowledge and Understanding}

Berys Gaut (2006), as an exemplar of the aesthetic cognitivist position, confirms the nomenclature of different kinds of knowledge, identified as part of the problem earlier, and which research in the visual arts can impart:

...most cognitivists correctly hold that there is a wide variety of different kinds of knowledge that art can impart to its appreciators: propositional knowledge, knowhow (skills), phenomenal knowledge (knowledge of what it is like to experience something), conceptual knowledge, knowledge of values and of significance, for example.

Notice here that the term cognitivism as I use it in this article embraces not only processes based upon deductive logic designed to construe propositional knowledge resulting in truths (justified or not) derived from the scientific method ${ }^{2}$ of inquiry - what Gilbert Ryle (1949) called 'knowing that'- but also processes based upon perceptual introspection designed to construe what has come to be adopted, problematically it now seems, as an antonym to cognition; experiential knowledge, (Ryle’s ‘knowing how').

Much well-intentioned effort has been expended in the attempt to legitimise those types of knowledge mentioned by Gaut as alternatives to the propositional knowledge assumed to be derived from the scientific method of research. But the resultant perceived split only serves to divide the research community, leaving practice-based or practice-led visual arts research in the position identified by Biggs and Buchler as isolationist.

Here is the nub of the confusion outlined in the problem identified earlier: experiential knowledge (and its variations) is not inimical to cognitive knowledge. Rather, it is a sub-set of cognitivism, non-propositional, and which delivers understanding, as valuable and socially-useful as propositional true beliefs, justified or not.

Indeed, Christoph Baumberger (2013: 62) argues that

... an epistemology of understanding is better suited than a theory of knowledge to do justice to the cognitive achievements of science, philosophy and the everyday; and that such an epistemology can and should accommodate a wide range of cognitive functions of artworks and provides a suitable epistemological framework for aesthetic cognitivism.

I am reminded of Peter Lamarque’s (2006: 129) pejorative phrase, the "slipperiness of cognitivism”, meant as a criticism of the use of the term 'cognitivism' to embrace the means towards both propositional and non-propositional knowledge, and would suggest that 'flexibility' is a more suitable qualifier, since he himself points out that nonpropositional knowledge can be derived from cognitivist activities he describes as “exploring aspects of experience” or "imagining possibilities”, whilst recognising that propositional knowledge delivers true beliefs. It should be noted here that both kinds of 
knowledge are derived from cognitive procedures, and are complementary: no clear opposition is implied between the two ${ }^{3}$.

\section{Art as a Means to Knowledge through Understanding}

The question is, how can exploring aspects of experience and imagining possibilities advance our understanding, and of what does it do this?

Much of our everyday experiences consists of encounters through language: notoriously arbitrary in terms of its relation to its referents and in the myriad of meanings exposed in its deconstructions, language is at once the source of our deepest illusions and our highest perspicacity. But we can also make sense of the world by applying a method of visual interpretation - imaginative interpretation, as Graham (1997: 57) puts it. In much the same way as we are not all blessed with an acute sense of scientific logic, so we are not all blessed with powers necessary to negotiate the nuances of language, which is where the visual arts and artists find a significant role:

Works of art can supply the imaginative appreciation of experience.... and their value derives from the fact that we may ourselves be deficient in this regard. This is the sense in which art is a source of understanding. (Graham 1997: 58)

We do not need to be limited by the scientific quest for confirmation of a measureable equivalence between our experience of the world and the material world itself; we do not need to be subject to the arbitrariness of language: visual art is another means to understanding, through which we may look in order to evaluate rather than to measure, to construe realities afresh.

As an example of practice which facilitates opportunities for us to re-evaluate conventions of understanding our perceived relationships with our physical environment, "to see beyond what is there” in the words of one of my anonymous referees, this article now considers a selection of the drawings and paintings produced by Robert A. Newell ${ }^{4}$ in part submission for his practice-based $\mathrm{PhD}$ to the University of Wales, subsequently featured in the exhibition Forms of Endurance and Change: 


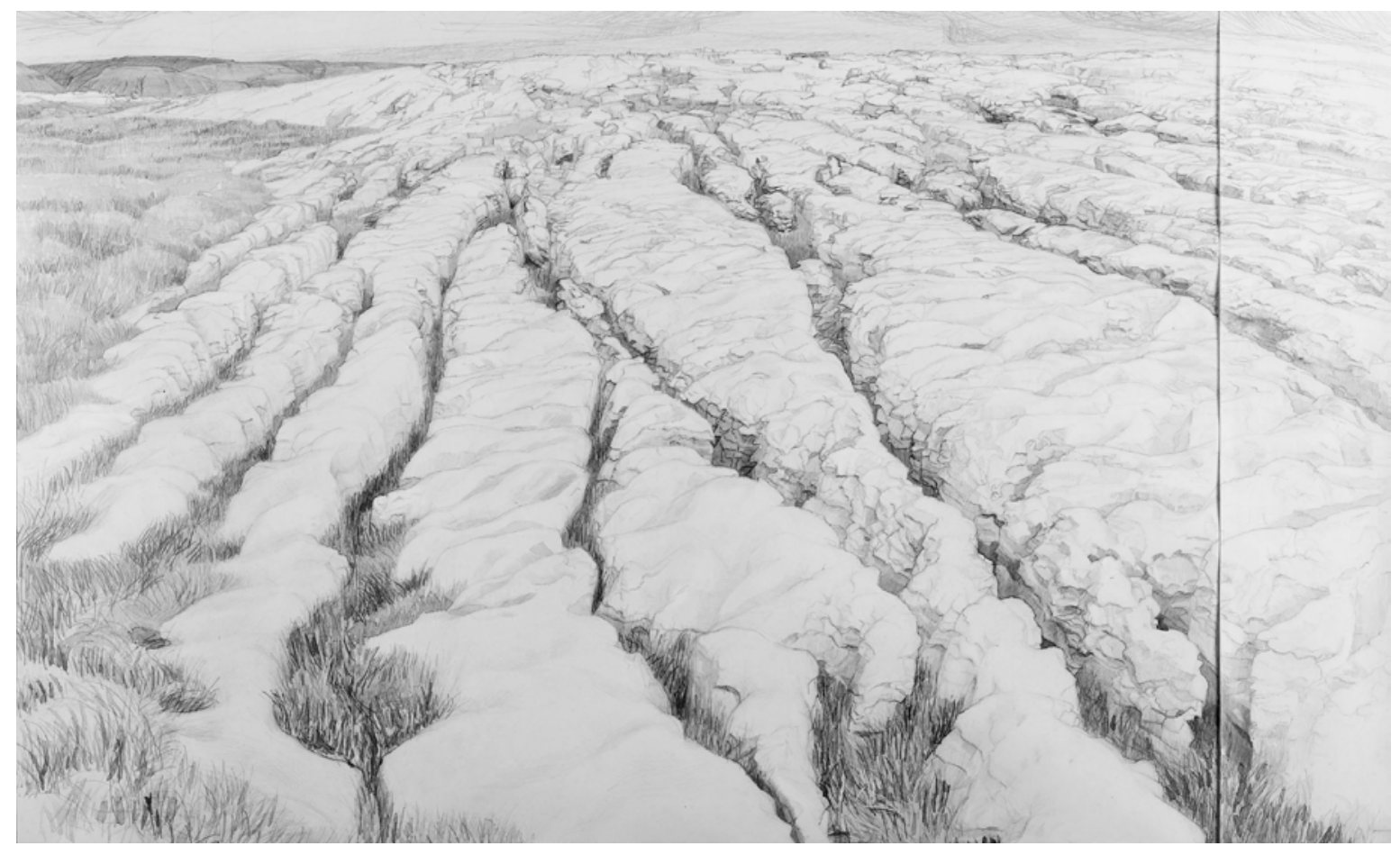

Fig. 1 Robert Newell Great Asby Scar I. Graphite pencil and watercolour on paper. $48.9 \times 78.8 \mathrm{cms}$

The viewer of this work is made aware from Newell's thesis about fundamental forces which form our shared physical world of land, sea and sky. They are invited to explore the shared psychological tensions which underlie the Heraclitean, oxymoronic constancy of change, the constant process of transformation of which we are too often unaware. These paintings and drawings show the fascinating effects of that process, and afford some understanding - knowledge - of our relationship with our physical surroundings because they challenge the viewer to resolve the tension between the concepts of an objective landscape and a subjective environment. In Newell's (2012: 3) words: “Painting and drawing are integral to an extended perceptual process that mediates the relationship between subject and object”. Consider these paintings and drawings: is the viewer gazing over a landscape outside themselves, or are they positioned within an environment, symbiotically-linked to their surroundings? Newell argues that perspective - the geometric projection system - actually serves to draw the viewer in to the picture, and if you look at the drawing Great Asby Scar I (Fig. 1) in particular, this point becomes evident: the viewer is afforded a much deeper insight even than that offered by Richard Wollheim's (1991: 105) twofoldedness, (in his sense of simultaneously perceiving the surface qualities and the illusory depths of space of the drawing itself), the viewer is offered a visual understanding of the twofold relationship with the space inhabited: how they are a part of it, and simultaneously apart from it, derived from the projective geometry of the drawing and how that compositional structure positions the viewer. Paul Klee, paraphrased by Arthur C. 
Danto (1991: 211), noted that “....art need not simply render the visible, but renders visible... we see by means of art something not to be seen in other ways, something in effect that must be made visible”. Here's the heart of Newell's drawings' intrigue, an intrigue worth exploring on the two levels introduced earlier: the perceptual, and the conceptual:

Consider again: do they intrigue the viewer's eyes? If so, how? Every one of the individual marks, and every combination of those marks at whatever level the viewer chooses to engage with these works, offers drawn visual equivalents for the natural phenomena in which their being is immersed yet rarely consciously experienced - land, sea, sky and their interactions with light. The visual psychologist James Jerome Gibson (1966: 238) had no doubt what artists are for: "The legitimate endeavour of working artists is to practise the art of structuring light”. Practising the art of structuring light is exactly what Newell does. Notice how at every level of illusory depth in the picture plane, from foreground to background, the scene depicted is in focus, edges are sharp. Now, this is not the way human natural perception system works. Humans are only able to focus on one plane at a time (if the reader doubts this, try the two fore-fingers test: hold them vertically in line, one close to the eyes, the other at arm's length: focus upon the nearer finger, and note the double image of the further finger?) This play on focus, by the way, is the source of that eerie, hyper-real, if not surreal quality of many of these rock-scapes. (See Great Asby Scar II, Fig. 2)

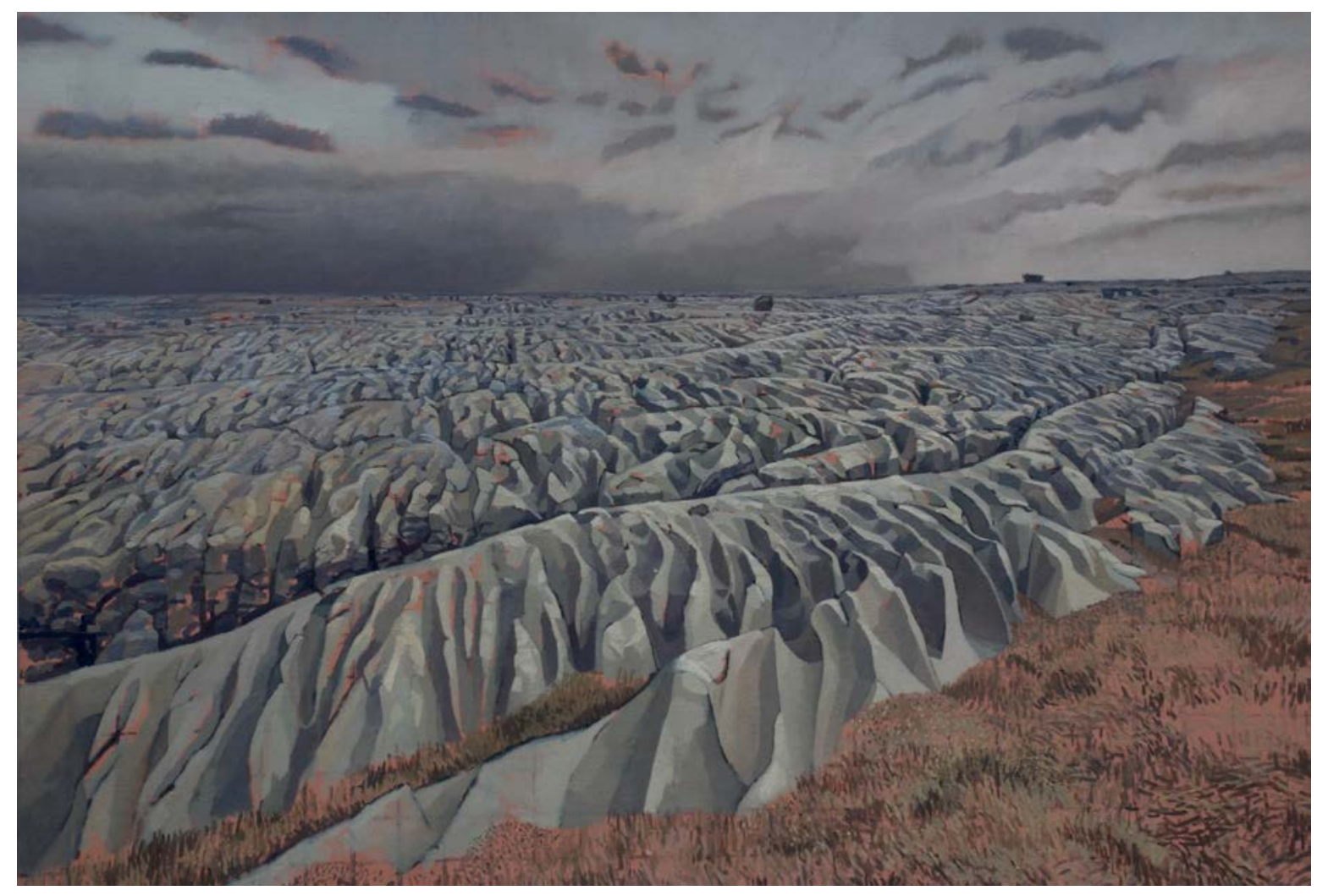


Fig. 2 Robert Newell Great Asby Scar II. Oil on canvas 106.7x152.5cms

So, if these drawings and painting are not records of natural perception, then what are they? These drawings are, in Newell’s (2013, personal communication) words, “...a synthesis of temporal looking...”. They represent time, as well as space: lengthy periods of time spent focussing on each individual surface and edge, time spent gradually building an understanding of structure beyond the reality of perception, a shareable understanding. Speaking of structure, notice the double structure apparent in Limestone Cliffs, Caim (Figs 3 and 3a), the Coldstream-esque pencil grid (meticulously made, sometimes with the aid of a spirit-level) mapping an underlying structure and thus affording the viewer an understanding of order underpinning the apparent chaos of disintegrating matter.

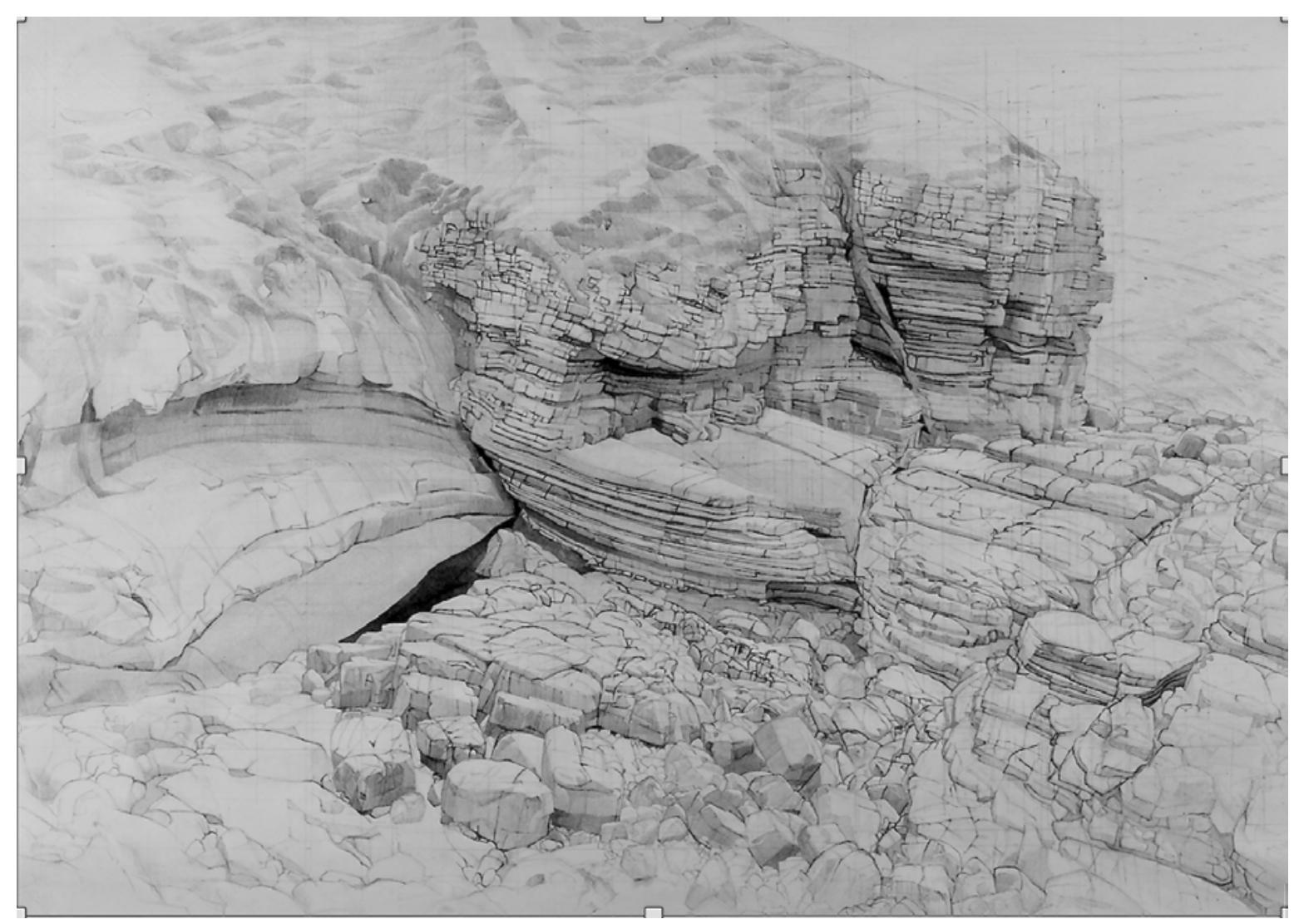

Fig. 3 Robert Newell Limestone Cliffs, Caim. Graphite pencil and watercolour on paper. $53.3 \times 73.6 \mathrm{cms}$ 


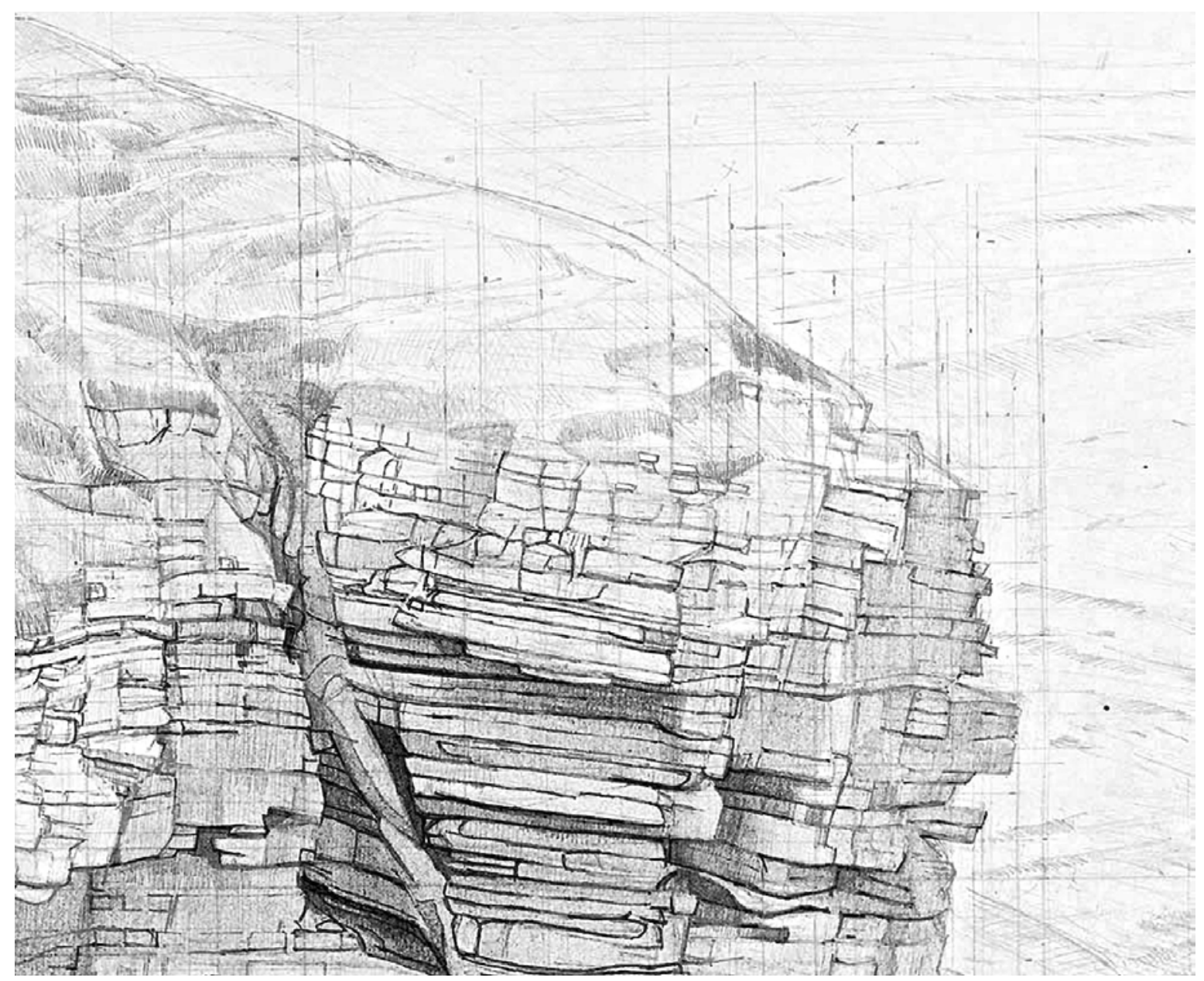

Fig. 3a Robert Newell Limestone Cliffs, Cain (detail)

Such drawings that reveal their construction process are a source of understanding unattainable by other reprographic means, and beyond that which can be expressed in words.

Newell's research allows the viewer insights to a range of perceptions of the world by over-riding their biological constraints: the familiar is made strange, to paraphrase Russian Formalist theorist Viktor Shklovsky (1977: 35).

What about the second kind of intrigue I mentioned? Do these drawings and paintings intrigue the brain? If so, how? Because so long as the viewer is willing to be engaged, they cannot fail to connect with an awesome concept: the ever-changing but hardly perceptible erosion of what Newell has called 'the bones of the land', under ever-changing lighting conditions, conceptually resonates - an appropriate Gibsonian notion - in the equivalent erosion of paper texture by the pencil's graphite grit or the abrasion of brush bristles against canvas weave. These works are about material on the move! So the viewer is afforded a balance between perceptual intrigue and conceptual intrigue: a hallmark of quality? Certainly a doorway to fresh insights, understanding and therefore knowledge. 
As Peter Goldie (2007: 166-7) argues:

There is a kind of cognitive value that many good conceptual artworks possess. These works can help us to think about certain difficult philosophical ideas. This is their cognitive value. So an artwork's being of cognitive value isn't restricted to its yielding knowledge in the form of propositional knowledge, of justified true beliefs. It can also be cognitively valuable in that it facilitates knowledge, and enhances our intellectual dispositions. This broader conception of cognitive value...helps us to explain an important fact: we can return to those artworks time after time and continue to find cognitive value in them, and this could not be explained if all they yielded were propositional knowledge.

\section{Summary}

With regard to research policy (regulations and requirements), it would be important to acknowledge the existence and importance of non-propositional/tacit knowledge, how it can be included under current requirements, and how research results can be communicated inclusive of its tacit component to facilitate application in practice. (Niedderer 2007: 12)

Until such time as universities’ research policies specify regulations and requirements governing practice-based research in the visual arts, this article is offered as an attempt to provide research supervisors, and others charged with advocating doctoral research proposals involving an aspect of visual arts practice, with a concise framework within which to argue their viability for “...contributing original knowledge and understanding in the field(s) of study concerned” (Frayling 1997: 9) within a multi-disciplinary academic research environment such as a university.

\section{Notes}

1 The Journal of Visual Arts Practice editorial policy has recently offered this clarification: "If a creative artefact is the basis of the contribution to knowledge, the research is practice-based. If the research leads primarily to new understandings about practice, it is practice-led". https://www.researchgate.net/project/Journal-of-Visual-ArtPractice-published-by-Taylor-and-Francis. (Accessed 15 May 2017). Earlier sources include Christopher Frayling's (1993: 5) distinction between research into art and design; through art and design; and for art and design. Research through art and design practices involves "studio work plus an extensive and substantial research report." This latter definition sounds very much like practice-based research; the two former definitions fit practice-led research. Hazel Smith and Roger Dean (eds.) 2009 Practice-led Research, Research-led Practice published by Edinburgh U.P. provides a comprehensive review of the various arguments.

2 Among the activities often identified as characteristic of science are: systematic observation and experimentation, inductive and deductive reasoning, and the formation and testing of hypotheses and theories. How these are carried out in detail can vary greatly, but characteristics like these have been looked to as a way of demarcating scientific activity from non-science. www.plato.stanford.edu (Accessed 20 April 2017) 
3 Paul Crowther's Phenomenologies of Art and Vision. A Post-Analytic Turn. (London: Bloomsbury, 2013) p.2 posits a "methodological bridge" between the two strands of the philosophical tradition of relevance to the acquisition of knowledge, which he identifies as analytic philosophy and existential phenomenology, arguing for a 'post-analytic phenomenology' which might alleviate the false dichotomy perceived between propositional and non-propositional knowledge at the core of misunderstandings experienced in research degrees' committees. He cites Richard Wollheim’s (1987) Painting as an Art as an example of the analytic philosophy position with a phenomenological emphasis, and as such, a useful bridge between the two.

4 Newell, Robert A. (2005) Landscape Painting: Redundant Genre or Viable Practice? (PhD Thesis. University of Wales, 2005). I'm grateful to Dr Newell for his permission to use illustrations of his paintings and drawings. Rob has been friend and colleague during our time teaching at the Swansea College of Art, University of Wales Trinity Saint David. His work can be seen at: robertnewellartist.co.uk

\section{References}

Baumberger C (2013) Art and understanding. In defence of aesthetic cognitivism. In: Bilder Sehen. Perspektiven der Bildwissenschaft. Regensburg: Schnell and Steiner. p. 62.

Biggs M and Buchler D (2008) Eight criteria for practice-based research in the creative and cultural industries. Art, Design \& Communication in Higher Education. 7(1): 5-18.

Danto A C (1991) Description and the phenomenology of perception. In: Bryson N Holly MA and Moxey K (eds) Visual Theory. Cambridge: Polity. pp. 201-215.

Denzin N and Lincoln Y S (eds) (2005) The Sage Handbook of Qualitative Research. $3^{\text {rd }}$ ed. Thousand Oaks CA: Sage.

Elgin C Z (2002) Art in the advancement of understanding. American Philosophical Quarterly. 39 (1): 1-12.

Elgin C Z (2006) From knowledge to understanding. In: Epistemology Futures. Oxford: Oxford U.P. pp. 199-215.

Findlow S (2012) Higher education change and professional-academic identity in newly 'academic' disciplines: The case of nurse education. Higher Education. 63:117133.

Fowles J (1980) The Aristos. (Revised ed) London: Triad.

Frayling C (1993) Research in art and design. RCA Research Papers 1(1):1-5.

Frayling C (ed) (1997) Practice-based Doctorates in the Creative and Performing Arts and Design. Litchfield: UK Council for Graduate Education. 
Gettier E L (1963) Is justified true belief knowledge? Analysis 23: 121-3.

Gibson J J (1966) The Senses Considered as Perceptual Systems. Boston MA: Houghton Mifflin.

Goldie P (2007) Conceptual art and knowledge. In: Philosophy and Conceptual Art. Oxford: Oxford U.P. pp. 157-170.

Goodman N (1978) Ways of Worldmaking. Indianapolis: Hackett.

Graham G (1997) Philosophy of the Arts. An Introduction to Aesthetics. London: Routledge.

Lamarque P (2006) Cognitive values in the arts: marking the boundaries. In: Kieran M (ed) Contemporary Debates in Aesthetics and the Philosophy of Art. Oxford: Blackwell. pp.127-142.

Macdonald S (1973) Articidal tendencies. In: Readings in Art and Design Education. Vol. 2: After Coldstream. London: Davis-Poynter. pp. 89-99.

Martin BR (2016) What is happening to our universities? (SPRU Working Paper Series, 2016) pp. 1-26. ISSN 2057-6668. Available at: www.sussex.ac.uk/spru/swps2016-03 (accessed 3 October 2017)

Newell R A (2012) Introduction, Forms of Endurance and Change. (Catalogue of exhibition held at Oriel Ynys Mon, 22 September - 4 November 2012 and Oriel Ceri Richards Gallery, Swansea, 11 January - 14 February 2013).

Niedderer K (2007) Mapping the meaning of knowledge in design research. Design Research Quarterly. 2 (2): 1-13.

Niedderer K (2007a) Analysing the meaning of knowledge in the definition of research, European Academy of Design Conference. Izmir, Turkey.

Ryle G (1949) The Concept of Mind. London: Hutchinson’s University Library.

Shklovsky V B (1977) Art as device. In: O’Toole LM and Shuckman A (eds) Russian Poetics in Translation. Vol. 4: Formalist Theory. Oxford: Holdan Books.

Wollheim R (1991) What the spectator sees. In: Bryson N Holly MA and Moxey K (eds) Visual Theory. Cambridge: Polity. pp. 101-150.

\section{Biographical Information}

Howard Riley is Professor Emeritus, Swansea College of Art, University of Wales Trinity Saint David. Head of the School of Research \& Postgraduate Studies 2004-14. He holds a University of Wales doctorate in the practice and pedagogy of drawing and a Master of Arts degree from the Royal College of Art. His drawings have been exhibited in Australia, Finland, Serbia, USA and UK. 